\title{
VOCES VITALES EL SALVADOR
}

\section{Entrevista a Verónica Castro}

Arquitecto, Maestría en Administración de Empresas, M.B.A., del INCAE. Ha formado parte de la junta directiva de Voces Vitales desde 2013. A la vez, participa en la junta directiva de la Fundación Ayúdame a Vivir y presidió la Asociación de Graduados de INCAE (AGI).

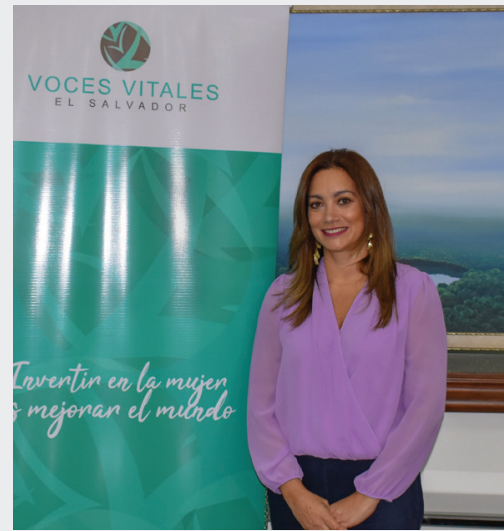

¿Cómo ven el avance en el país del empoderamiento femenino como un medio para erradicar la discriminación, la brecha salarial y la violencia contra la mujer?

El empoderamiento femenino es un tema que cada vez se está escuchando más. Hablamos de que las mujeres estamos abriéndonos un espacio en todos los lugares donde nos desempeñamos. Sin embargo, en muchos casos no se observan acciones concretas que nos permitan eliminar la discriminación, la brecha salarial y la violencia contra las mujeres. Se necesita que nosotras nos cuestionemos sobre nuestras capacidades y que demostremos que, como los hombres, podemos hacer muchas cosas en cualquier ámbito; desde los lugares de trabajo se debe procurar el equilibrio con posiciones laborales y salarios iguales, por ejemplo, hay empresas que ahora no ven fotografía ni nombre de un candidato, sino sus capacidades, y eso es bueno.

Las mujeres cada día nos estamos educando más, también conociendo más sobre nuestros derechos. Por nuestra parte, debemos ser conscientes de dónde estamos y de lo que queremos lograr en todos los aspectos de nuestra vida, en nuestra profesión, en la vida familiar, personal, etc., y también pensar la manera en que lo vamos a lograr. Lo que cada una haga desde su lugar es importante y abona a que el empoderamiento femenino sea una realidad.

¿Cómo surge Voces Vitales? ¿Cuál es el principal objetivo de Voces Vitales en El Salvador?

Voces Vitales El Salvador se pone en marcha en septiembre del 2008 por un grupo de líderes salvadoreñas creen firmemente que el empoderamiento de las mujeres y el fortalecimiento de su potencial y liderazgo; tiene un impacto significativo en sus vidas, sus comunidades y la nación en general.

En el país, trabajamos específicamente para lograr el empoderamiento económico de las mujeres, alentán- dolas a desarrollar y ejercitar sus habilidades; lo hacemos a través de la educación, la mentoría y las redes de negocios. Buscamos que las mujeres sean agentes de cambio y transformen su vida, la de su familia, su lugar de trabajo y su comunidad.

¿Quiénes son los actores clave que participan en todo el esfuerzo que realiza Voces Vitales?

Atendemos a mujeres líderes, profesionales, empresarias y emprendedoras, a quienes les brindamos herramientas para que adquieran nuevas aptitudes y conocimiento, a través de nuestra Red de Mujeres de Negocio, de nuestros programas de mentoría y de asistencias técnicas. Ellas son las principales, sus ganas de tomar la rienda de su vida y de mostrar sus capacidades.

Nuestro equipo, desde la Junta Directiva hasta cualquier persona que busca y trabaja oportunidades para las salvadoreñas.

Asimismo, trabajamos de la mano con organizaciones afines, empresa privada, entre otros, que brindan herramientas para el desarrollo a las mujeres corporativas y empresarias, que son la razón de ser de nuestra institución.

¿Cómo ha sido la respuesta a todos esos esfuerzos de la principal beneficiaria de Voces Vitales: la mujer salvadoreña?

Durante los casi 11 años de Voces Vitales en El Salvador, hemos establecido un programa de mentoría exitoso que nos permite apoyar el desarrollo personal y profesional de las mujeres a las que servimos, despertando el interés de microempresarias, pero también de grandes empresas que buscan desarrollar el talento humano con el que cuentan. 
Además, muchas microempresarias buscan ser parte de nuestra Red de Mujeres de Negocios, donde impartimos temas de actualidad para las empresas, cómo sacar un costeo, cómo utilizar herramientas virtuales, y aspectos personales. Asimismo, dentro de ella, se da la oportunidad de formar redes que resultan fundamentales para el apoyo y el crecimiento de las emprendedoras.

A lo largo de estos años, también hemos desarrollado diferentes eventos en los que expertos mundiales nos hablan sobre negocios y emprendimiento, lo cual permite la actualización de conocimientos y que tengamos una mejor visión sobre el camino que deben seguir las empresas.

¿Considera que la perspectiva de la mujer empresaria es diferente a la de un hombre? ¿Ella debería ser más humana, solo por ser mujer?

Somos testigos de que algunas empresas están promoviendo la presencia de mujeres en altos puestos. Esto se da debido a que muchas mujeres están mostrando sus habilidades y siendo valoradas dentro de ellas. Es una realidad que las mujeres tenemos diferente forma de pensar que los hombres, vemos el mundo de distinta manera, y en esas diferencias es donde se encuentra la riqueza, porque todos podemos aportar, desde nuestro rol. Todos podemos aportar ideas valiosas que hacen mejorar las organizaciones.
¿Qué significa liderazgo para Voces Vitales? ¿Cuál es la característica de las mujeres líderes?

El liderazgo del que hablamos en Voces Vitales es ejercido por aquellas personas que utilizan sus capacidades, credibilidad y conexiones para beneficiar a otros. En pocas palabras es dar el ejemplo, en nuestra familia, comunidad, empresa. El poder que podamos tener como líderes, es necesario que lo usemos para empoderar a otros.

Liderazgo, es la manera en que podemos influir en las personas que nos rodean en los diferentes roles que desempeñamos y en cambiar la realidad. Las mujeres tenemos esa capacidad de influir, somos apasionadas para hacer lo que nos gusta, somos protectoras por naturaleza, entre otras características. Las mujeres líderes se preocupan por los demás, pero también por sí mismas, sabemos que, para poder desempeñarnos de la mejor manera en todos nuestros roles, primero debemos estar bien nosotros mismas y de esa manera, es posible dar lo mejor.

¿Qué logros más significativos ha alcanzado Voces Vitales en su esfuerzo por capacitar a la mujer salvadoreña hacia el empoderamiento económico?

Es importante destacar la cantidad de mujeres salvadoreñas a las que hemos podido llegar desde nuestro nacimiento, a través de todos los proyectos que hemos desarrollado con la ayuda de muchas instituciones. Por ejemplo:

\section{PROGRAMA/ACCIÓN}

TALLERES DE CAPACITACIÓN

Red de Mujeres de Negocios, CRECEMUJER, EMPRENDEMUJER, CAFE MUJER (2013 -2018)

PROGRAMA DE MENTORIA

Incluye Caminatas de Mentoría (2013 - 2018)

PROYECTOS

Talleres de formación/capacitación y asistencias técnicas individuales (2013 - 2018)

\section{Beneficiadas}

8,145

786

3,118

\section{2,049}

Hemos escuchado testimonios de personas que han recibido un par de horas de mentoría. En una ocasión, una aprendiz mencionaba que estaba por cerrar su negocio, y al recibir nuestro apoyo ha podido ver las cosas de manera diferente, tener otra visión y seguir adelante. Hace falta conversar sobre estos temas de negocios entre nosotras y apoyarnos. 
También quiero mencionarles que gracias a las diversas intervenciones de VVES con diferentes programas, las beneficiarias han tenido impactos en sus negocios, por ejemplo, en algunos que se derivan del apoyo recibido de parte de USAID, se ha generado:

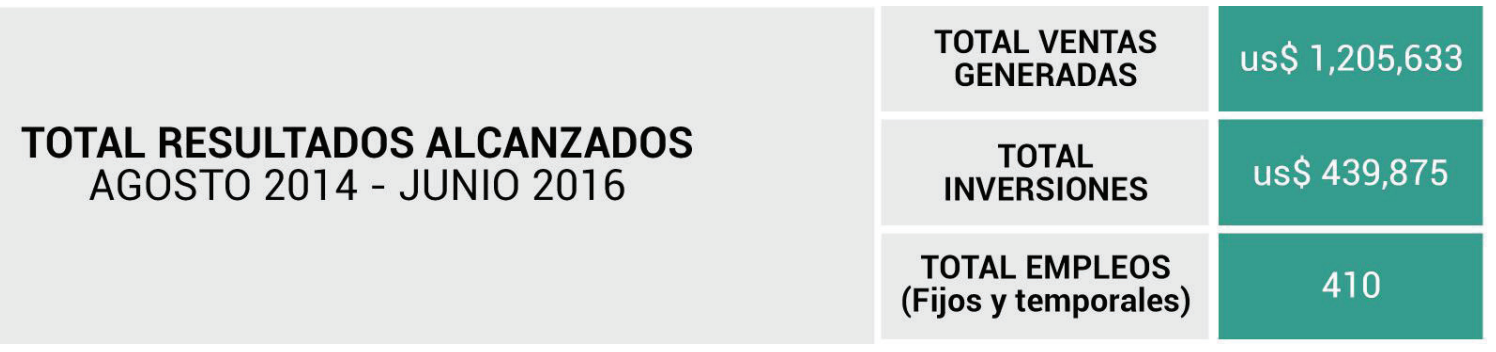

Otro de nuestros programas está dirigido para

¿Qué cobertura tiene Voces Vitales a nivel nacional?

La gran mayoría de acciones de VVES son desarrolladas en el área metropolitana de San Salvador, que es también donde se concentra la mayor parte de la actividad económica del país y por lo tanto el parque empresarial salvadoreño. No obstante, hemos realizado actividades en Santa Ana y en San Miguel con los diversos servicios ofrecidos. A esos municipios han asistido dueñas de negocios, empresarias y jóvenes mujeres con ideas de negocios que residen en los municipios aledaños a los mencionados. Hacia el año 2013, tuvimos la oportunidad de participar en el Proyecto de USAID para la Competitividad Municipal, en donde formamos cerca de 475 mujeres provenientes de los 50 municipios en los cuales fue ejecutado el proyecto.

Actualmente, estamos trabajando con jóvenes desde los 18 años que cuentan con idea de negocio, y desde El Salvador estamos coordinando un programa a nivel regional, de la mano con otros capítulos de Voces Vitales en Centroamérica.

¿Cuáles son los proyectos futuros más importantes de Voces Vitales?

Desde el año 2016, hemos venido ejecutando proyectos de mentoría a nivel regional con el apoyo de la Fundación Citi y de los cuales Voces Vitales ha sido el ente coordinadora nivel regional para tres países (Honduras, Guatemala y El Salvador) y con ello queremos consolidar el posicionamiento de VVES como hub (núcleo-impulsor) de las iniciativas que apoyan el empoderamiento económico femenino en Centroamérica y entre los capítulos de Voces Vitales de la región. mujeres de 25 a 50 años, se está inciando en El Salvador, Guatemala y Costa Rica, atendiendo a microempresarias que quieran hacer crecer su negocio.

De igual forma, se espera continuar trabajando con la empresa privada, en programas de mentoría "in house" (crecimiento profesional al interior de las empresas) y con ello ampliar este campo de acción para mujeres profesionales/corporativas. Como Voces Vitales nos sumamos al esfuerzo de estas empresas que quieren desarrollar a sus colaboradores por medio de este servicio.

Este año estamos aplicando a otros proyectos para ser socios implementadores de procesos relacionados con emprendimiento y desarrollo empresarial para poblaciones en condiciones de vulnerabilidad.

¿Cómo puede una mujer salvadoreña convertirse en beneficiaria de los programas que Voces Vitales imparte?

Cualquier mujer que esté económicamente activa y requiera de nuestro acompañamiento puede contactarnos y beneficiarse de nuestros programas, acercándose a nuestra organización a través de nuestras redes (Voces Vitales El Salvador, en Facebook, Twitter e Instagram), llamándonos (al 2219-6529) o a través de nuestro correo electrónico (coordinacion@vocesvitales.org.sv). Durante el año lanzamos diferentes programas y eventos que pueden estar dirigidos a su perfil y que pueden servirle para su crecimiento personal y profesional. 